\title{
Study of Etiological Profile of Nasal Septal Perforation
}

\author{
Vivek Samor ${ }^{1 *}$, Prashant Pachar ${ }^{2}$, N K Soni ${ }^{3}$ \\ ${ }^{1 *}$ Assistant professor, 2 PG Resident (Illrd Year), ${ }^{3}$ Ex. Professor \& Head, \\ Department of ENT, S P Medical College, Bikaner, Rajasthan, India.
}

\begin{abstract}
Introduction: Perforation of the nasal septum is a curious clinical entity. Many a time being inconspicuous and symptomless, this is often missed in routine clinical check-up unless and until special attention is paid to it during examination, and at occasions, it may be a presenting feature of a local or even of a systemic disease. Lack of systemic study on the subject in recent year prompted the authors to collaborate the old recorded case and to conduct the present study.

Materials and Methods: From January 2001 to December 2015, 80 patients with perforation of nasal septum have been examined in department of Otorhinolaryngology and head and neck surgery, PBM Hospital and SP Medical College, Bikaner, Rajasthan (India).

Results: The most frequent age of presentation of nasal septum perforation was third and fourth decades (total 35 cases). Youngest patient was a child of 5 years age and the oldest was aged person of 82 years. 45 cases were males and 35 were females.

In 52 cases, the perforation was in the cartilaginous portion of the nasal septum which were the cases of digital picking group, culture and customs group and surgical and other form of local trauma, other were due to diseases like atrophic rhinitis, tuberculosis leprosy and scleroma. In 12 cases, perforation was in bony portion while both the parts were found to be
\end{abstract}

\section{INTRODUCTION}

Perforation of the nasal septum is a curious clinical entity. Many a time being inconspicuous and symptomless, this is often missed in routine clinical check-up unless and until special attention is paid to it during examination, and at occasions, it may be a presenting feature of a local or even of a systemic disease. Various causes of perforation have been demonstrated in the literature like selfinflicted (Barton 1977, Harris \& Barton 1989)1,2 or surgical trauma, in held necrotizing age or certain industrial process being most common causes in developed countries. Other causes include neoplasm's (Raddington young 1979) ${ }^{3}$ and midline granuloma (Fried mann 1978). ${ }^{4}$ In developing countries like India, specific infection such as tuberculosis, leprosy, syphilis, myiasis are still common diseases causing nasal septum perforation. Syphilitic perforation of nasal septum has been extensively documented in literature (Bedi and Arunthanthi 1971). ${ }^{5}$

Septal perforations disturb the natural laminar airflow through the nose, creating turbulence and disrupting normal humidification. involved in rest of the cases. It is important to point out that syphilitic lesion more frequently affects the bony portion.

The size of perforation varied, the smallest being 2 to $3 \mathrm{~mm}$ diameter and largest being 4 to $5 \mathrm{cms}$.

Conclusion: 80 cases nasal septal perforation of diverse etiology were studied. It reveals that traumatic and iatrogenic post-surgical were common causes of septal perforation, indicating shifting from the old era of syphilis to be common, in the part of countries, however infectious diseases were also found to be etiological factors that have been seen rarely in developed countries.

Key Words: Nose, Septal perforation, Management.

\section{${ }^{*}$ Correspondence to:}

\section{Dr. Vivek Samor,}

Assistant professor, Department of ENT,

S P Medical College, Bikaner, Rajasthan, India.

\section{Article History}

Received: 24-06-2016, Revised: 08-07-2016, Accepted: 30-07-2016

\begin{tabular}{|l|c|}
\hline \multicolumn{2}{|c|}{ Access this article online } \\
\hline $\begin{array}{l}\text { Website: } \\
\text { www.ijmrp.com }\end{array}$ & Quick Response code \\
\hline DOI: & \\
10.21276/jmrp.2016.2.4.038 & \\
\hline
\end{tabular}

This process can cause a range of symptoms including recurrent epistaxis, crusting, discharge, nasal obstruction, anosmia, pain, and whistling. 6,7 The structural support of the nose may be compromised in larger perforations, causing external deformities, ${ }^{6}$ saddle nose deformity, Broad bulbous nasal tip. The clinical presentation can vary greatly between patients depending on the size and location of the perforation. Larger and more anterior perforations are thought to be the most likely to cause symptoms and explains why some patient remain asymptomatic while others experiencing debilitating symptoms. ${ }^{7-9}$

Expect for a few scattered reports on some special lesions, the study on nasal septum perforation with its diverse etiology in the collective and comprehensive form is yet lacking in the literature. No doubt, such perforation of the nasal septum presents a peculiar enigma to the reconstructive nasal surgeon. They exist as clear tissue voids at time overt, more often occult and tantalizingly invite surgical repair. But certainly we do not mean to 
dis down this region and leave it out of scope. Lack of systemic study on the subject in recent year prompted the authors to collaborate the old recorded case and to conduct the present study.

\section{MATERIALS AND METHODS}

From January 2001 to December 2015, 80 patients with perforation of nasal septum have been examined in department of Otorhinolaryngology and head and neck surgery, PBM Hospital and SP Medical College, Bikaner, Rajasthan (India). Each case has been carefully assessed from etiological stand point with the help of laboratory and radiological investigations and if required histopathological examinations.

\section{OBSERVATIONS}

The most frequent age of presentation of nasal septum perforation was third and fourth decades (total 35 cases). Youngest patient was a child of 5 years age and the oldest was aged person of 82 years. 45 cases were males and 35 were females.

The duration of the condition varied from days to years depending upon the causes. Clinical history was also rebated with the cause of the diseases.

In 52 cases, the perforation was in the cartilaginous portion of the nasal septum which were the cases of digital picking group, culture and customs group and surgical and other form of local trauma, other were due to diseases like atrophic rhinitis, tuberculosis leprosy and scleroma. In 12 cases, perforation was in bony portion while both the parts were found to be involved in rest of the cases. It is important to point out that syphilitic lesion more frequently affects the bony portion. The size of perforation varied, the smallest being 2 to $3 \mathrm{~mm}$ diameter and largest being 4 to $5 \mathrm{cms}$. Some of the patients came to us with this complaint only. Nearly half of the patients presented with other nasal symptom also while other patient were not aware of the condition and this finding was incidental for them. Some persons who have perforation of septum as result of piercing it according the religious reasons or cultural customs were aware for it but they did not bother for the condition.

From 80 cases of septal perforation, about half (38) were found in traumatic group of varied etiology. Among there the common causes are post traumatic septal abscess, repeated cautry and post-surgical, digital picking.

In inflammatory group, causes of perforation could be detected as syphilis (2 cases), Leprosy (2 cases), atrophic rhinitis (2 cases) or myiasis ( 2 cases) and tuberculosis ( 1 case).

Nasal tumours as cause of septal perforation were found only in 8 cases (10\%).

Among foreign bodies cases, Button battery was found to be responsible for septal perforation in two cases. Other etiological factors are shown in Table 1.

Table 1: Causes of nasal septum perforation

\begin{tabular}{|c|c|c|}
\hline \multicolumn{2}{|c|}{ Causes } & \multirow{2}{*}{$\begin{array}{c}\text { Number of } \\
\text { cases }\end{array}$} \\
\hline I. & Trauma & \\
\hline & 1. Post-surgical & 7 \\
\hline & 2. Post Traumatic Septal abscess & 11 \\
\hline & 2. Repeated septal cautery & 12 \\
\hline & 3. Digital Picking & 8 \\
\hline II. & Inhalational Intra nasal steroid & 1 \\
\hline \multirow[t]{9}{*}{ III. } & Inflammatory conditions & \\
\hline & 1. Furuncle & 1 \\
\hline & 2. Syphilis & 2 \\
\hline & 3. Tuberculosis & 1 \\
\hline & 4. Leprosy & 2 \\
\hline & 5. Rhinoscleroma & 1 \\
\hline & 6. Atrophic rhinitis & 2 \\
\hline & 7. Myiasis & 2 \\
\hline & 8. Invasive Fungal granuloma & 1 \\
\hline \multirow[t]{6}{*}{ IV } & Nasal Tumours & \\
\hline & 1. Squamous cell carcinoma & 4 \\
\hline & 2. Adenocarcinoma & 1 \\
\hline & 3. Adenocystic carcinoma & 1 \\
\hline & 4. Olfactory neuroblasma & 1 \\
\hline & 5. Fibroangioma & 1 \\
\hline \multirow[t]{4}{*}{ V. } & 1. Midline lethal granuloma & 1 \\
\hline & 2. Rhinolith & 2 \\
\hline & 3. Foreign body (Button battery) & 4 \\
\hline & 4. Unknown & 2 \\
\hline VI. & 1. Piercing (Culture group) & 12 \\
\hline
\end{tabular}




\section{DISCUSSION}

Septal perforations are caused by an injury to nasal septum, affection of mucoperichondrium causing diminished blood supply which can result in cartilage and mucosal necrosis. After perforation, mucosal edged epithelize, preventing the closure of the defect.

The Nasal septum is very delicate and can be easily injured by trauma (Nasal Fracture), infection (MRSA), Chronic granulomatous diseases, medication or drug abuse (nasal decongestants, nasal steroid or cocaine), auto immune conditions and by prior surgery such as septoplasty or rhinoplasty or submucous resection of nasal septum surgery. In the present study, unfortunately, the majority of perforations of nasal septum are iatrogenic in origin. latrogenic causes include nasal septal surgery, nasal intubation, nasogastric tube placement etc. Overall nasal septal surgery was most common cause of septal perforation.

Submucosal resection of the septum is reported to have a much higher incidence of septal perforation than septoplasty, and estimates quote $17-25 \%$ and $1.4-5 \%$ respectively. ${ }^{10,11} \mathrm{~A}$ perforation is much more likely to arise if the mucosa has been torn or removed in adjacent parts of the mucosa. Tardy (1973) expressed his opinion that changing from the classic submucous resection surgery to a more progressive and conservative septoplasty approach, post-operative perforation have diminished in frequency. Although the septoplasty procedure does not give complete immunity against this complication, perforation is still less commonly encountered with the endoscopic septoplasty. ${ }^{12}$

Nasal septal perforation may affect either the bony or cartilaginous portion of septum. Most commonly it affects the anterior septal cartilaginous area although, tertiary syphilis characteristically affects the bony septum, which is diagnosed by other manifestation like perforation of the palate, depressed bridge of the nose, gumma of the skin and aortic aneurysm with positive VDRL. ${ }^{13}$ However, some of these manifestations can occur in other diseases like rhinoscleroma, rhinolith and in midline lethal and invasive fungal grannuloma. ${ }^{14}$ Syphilitic cases have good response with antibiotic therapy when active lesion is present ${ }^{15}$ and scleroma and tuberculosis showed slow recovery even in 3 to 6 months and can be confirmed by biopsy. However, in most cases of syphilitic origin, the perforation of the septum is extensive as to destroy the most of the bony and ultimately cartilagenous portion as well. The present study showed that nasal septum perforation should also be assessed from chronic granulomatous disease even in the present era.

A number of chronic inflammatory and granulomatous diseases, including sarcoidosis, relapsing polychondritis, systemic lupus erythematosis, Crohn;s disease and dermatomyositis are associated with septal perforation. However, the most likely and most important diagnostically is Wegener' s Granulomatosis, now known as granulomatosis with angiitis. The latter is potentially lethal due to the risk of renal failure and can also destroy most of the nasal septum resulting in very large perforations and external saddle deformity. Cocaine abuse can be associated with a Wegener's type reaction and cause massive septal perforation and perforation of the hard palate. ${ }^{16}$ The other etiological factors reported in literature like acute infections disease such as diphtheria, scarlet fever, typhoid fever and chronic disease such as scleroderma rheumatoid arthritis, psoriatic arthritis, blood dyscrasias, systemic lupus erythematosus, chronic relapsing perichondritis have not be found in the present study however 2 Cases of atrophic rhinitis have perforation of nasal septum. ${ }^{17-22}$

Nasal tumour must be considered and search for, if nasal septal integrity is compromised. There were 8 cases of neoplasm having septal perforation in the present study. Benign tumor causes perforation by pressure atrophy of the bone or cartilage. Malignant neoplasm may directly invade the septum. In general, the mechanism of a septal perforation consists of ischaemia, and ulceration of the overlying mucosa with subsequent chondrolysis.

Repeated septal cautery for controlling epistaxis is not uncommon to blame for small or medium sized anterior septal perforations. 12 patients have been found to have perforation by repeated septal cautery.

Factitious digital trauma (nose picking) predisposes to septal scarring and avascular necrosis. 8 cases of the series had no obvious disease and had a habit of nose picking. Similar cases of nasal septum perforation have been reported by Barton, and Harris \& Barton. ${ }^{1,2}$

As nasal trauma increases in all age groups (auto-accident, muggings, sport league eg. baseball and junior hockey and cricket), more undiagnosed septal hematoma occurs. Subsequently septal abscess with perforation may result. In the present series, there were only 11 such cases.

Nasal piercing has also been found as a direct cause of nasal septal perforation. In this part it is as result of family tradition, culture and social factors in some of the community. Nasal piercing indirectly may be seen as a result of long term topical drug application like ethyl phenidate, methamphetamine and cocaine.

The diagnosis of serious systemic or local disease which may present or cause a perforation of the nasal septum is of prime importance. The patient may be genuinely unaware of perforation or unwilling to admit to drug abuse or to have sexual contact for social or legal reasons.

In addition to complete physical examination, all possible haematological or serological investigations should be performed to make a diagnosis. It is also clearly of paramount importance to exclude such condition as midline lethal granuloma or neoplasm by histopathological examinations of a local tissue. Similarly the granulomatous lesion affecting the nasal septum causing perforation like leprosy, invasing fungal granuloma, syphilis, tuberculosis, scleroma be evaluated by taking the biopsy from the margin of the septal perforation. However, there is a significant group of the patient in which no specific etiological factor can be demonstrated. In such a situation periodic checkup and review of such patients should be advised.

\section{CONCLUSION}

80 cases nasal septal perforation of diverse etiology were studied. It reveals that traumatic and iatrogenic post-surgical were common causes of septal perforation, indicating shifting from the old era of syphilis to be common, in the part of countries, however infectious diseases were also found to be etiological factors that have been seen rarely in developed countries. Other contributing factors of the condition are also being discussed special attention is drawn to thus clinical features as a diagnostic sign of local and systemic diseases. 


\section{REFERENCES}

1. Barton RPF. Massive self inflicted perforation of the nasal septum. J Laryngol Otol. 1977; 91:173-176.

2. Harris TM, Barton RPF. Perforation of nasal septum with non specific aetiology. J Laryngol Otol. 1980; 94:789-791.

3. Raddington Young J. Malignant tumours of the nasal septum. J Laryngol Otol. 1979; 93: 817-820.

4. Friedmann I. lodiopathic pleomorphic mid facial granuloma. J Laryngol Otol. 1978; 92: 601-604.

5. Bedi MS, Arunthathi S. Syphilitic perforation of the nasal septum Ind J Dermatol veneriol. 1971; 38:15-20.

6. Rokkjær MS, Barrett TQ, Petersen CG. Good results after endonasal cartilage closure of nasal septal perforations. Dan Med Bull. 2010; 57: A4196.

7. Romo T 3rd, Sclafani AP, Falk AN, Toffel PH. A graduated approach to the repair of nasal septal perforations. Plast Reconstr Surg. 1999; 103: 66-75.

8. Teymoortash A, Werner JA. Repair of nasal septal perforation using a simple unilateral inferior meatal mucosal flap. J Plast Reconstr Aesthet Surg. 2009; 62: 1261-1264.

9. Lumsden A, Shakeel M, Ah-See KL, Supriya M, Ah-See KW and Ram B. Management of Nasal Septal Perforation: Grampian Experience. Austin J Otolaryngol. 2015;2(4): 1041; 4 pages.

10. Bateman ND, Woolford TJ. Informed consent for septal surgery: the evidence-base. J Laryngol Otol. 2003; 117(3):186 9.

11. Dommerby H, Rasmussen OR, Rosborg J. Long-term results of septoplastic operations. ORL J Otorhinolaryngol Relat Spec. 1985; 47(3): $151-7$.

12. Tardi ME, Septal perforation. Otolarygnol Clinics North America 1973; 6: 711-715.

13. Dutta A.K, Mishra BL, Ghosh S. Skeletal manifestations of late syphilis. Ind J Dermatol Veneriol Leprosy 1965; 31:118-120.

14. Soni NK, Chatterji P, Nahata SK, Lal BB. Perforation of the palate in scleroma. Ind J Dermatol veneriol leprosy 1980; 46: 375376.
15. Pletcher SD, Cheung SW. Syphlis and Otolaryngology. Otolarygnol Clinics North America 2003;36: 595-604.

16. Andrew C. Swift, Samuel C. Leong. Nasal septal perforation: causes and management options. Journal of ENT Masterclass; 2013, 6(1); 66-71.

17. Mathews, J.L., Ward, J.R., Samuelson, C.O. et al. Spontaneous nasal septal perforation in patients with rheumatoid arthritis; Clin Rheumatol (1983) 2: 13. doi:10.1007/BF02032063

18. Snyder, Mc carthy RE, Toomey JM, Rothfield NF. Nasal perforation in SLE. Arch otolaryngol 1974;99:456-457.

19. Chan TV, Spiegel JH. Klebsiella Rhinoscleromatis of the memb. Nasal septum. J Laryngol Otol. 2007; 121: 998-1002.

20. Zeitlin JF, Tami TA, Baughmann $R$ et al. Nasal and sinus manifestations of Sarcoidosis. Am J Rhinol. 2000; 14: 157-161.

21. Aubart FC, Ouayoun M, Brauner M, ET AL. Sinonasal involvement in Sarcoidosis, A case control study in 20 patients. Medicine (Baltimore)2006; 85: 365-371.

22. Yang C, Talbot JM, Hwang PH. Bony abnormalities of PNS in patients with Wegner's granulomatosis. Am J Rhinol. 2001; 15: 121-125.

Source of Support: Nil. Conflict of Interest: None Declared.

Copyright: (c) the author(s) and publisher. IJMRP is an official publication of Ibn Sina Academy of Medieval Medicine \& Sciences, registered in 2001 under Indian Trusts Act, 1882.

This is an open access article distributed under the terms of the Creative Commons Attribution Non-commercial License, which permits unrestricted non-commercial use, distribution, and reproduction in any medium, provided the original work is properly cited.

Cite this article as: Vivek Samor, Prashant Pachar, N K Soni. Study of Etiological Profile of Nasal Septal Perforation. Int J Med Res Prof. 2016; 2(4):159-62. 